\title{
PHILOSOPHY
}

\section{DEMERS TEORETIC PRIVIND EPIFENOMENUL VIAȚĂ - MOARTE}

\author{
Oana Gabriela S,orodoc, prof. \\ Școala Gimnazială Găinești \\ ROMÂNIA - Găinești \\ DOI: https://doi.org/10.31435/rsglobal_ws/12072018/6003
}

\section{ARTICLE INFO}

Received: 01 May 2018

Accepted: 21 June 2018

Published: 12 July 2018

\section{KEYWORDS}

life,

death,

epiphenomen,

folk,

customs

\begin{abstract}
This article is a tiny piece of research about what LIFE and DEATH mean, seen as customs. The last one is a epiphenomen of LIFE and it represents, for all of us, an ocassion of meditation.

I have tried to present a small, but representative part of the Geto Dacian heritage of these customs, those related to LIFE and DEATH becouse in this area we can corelate the "stones speech" (the archaeological finds) with the "soul speech" (the historical testimonies, the folk treasure).
\end{abstract}

Citation: Oana Gabriela Şorodoc. (2018) Theoretical Approach on the Epiphenomen Life - Death. World Science. 7(35), Vol.1. doi: 10.31435/rsglobal_ws/12072018/6003

Copyright: (C) 2018 Oana Gabriela Sorodoc. This is an open-access article distributed under the terms of the Creative Commons Attribution License (CC BY). The use, distribution or reproduction in other forums is permitted, provided the original author(s) or licensor are credited and that the original publication in this journal is cited, in accordance with accepted academic practice. No use, distribution or reproduction is permitted which does not comply with these terms.

Introducere. Omul... Definit ca măsură a tuturor lucrurilor ${ }^{1}$, sau biată fărâmă de praf rătăcind printrun Univers prea mare şi rece - neînţeles şi copleşitor - în căutarea sensului Vieţii sale şi al lumii, deși a avut uneori cheia potrivită, de cele mai multe ori fără a şti că o are chiar din orizontul Creației, a ajuns să nu-și mai regăsească sensul. Moartea - ca de altfel şi Viaţa - este pentru toți prilej de meditaţie. Am ales să evoc în lucrarea de cercetare o parte infimă dar definitorie din moștenirea daco-getică a acestor obiceiuri ${ }^{2}$ - cele legate de momentele de Viață și Moarte, pentru că în acest domeniu putem corela ,,graiul pietrelor” (Lc.19,40) (descoperirile arheologice) cu graiul sufletelor (mărturiile istorice ${ }^{3}$, tezaurul folcloric) şi putem arăta că atunci când rostim cuvântul $d o r^{4}$, când participăm la un alai funerar sau când slăvim Cerurile coborâte pe Pământ la

\footnotetext{
${ }^{1}$ Cf. PROTAGORAS din Abdera (487 îHr. - 420 îHr.): „omul este măsura tuturor lucrurilor, şi a celor care există precum există, și a celor care nu există, precum nu există”. A se vedea PLATON, Theaitetos (152a), în Opere, (vol.VI), trad. Constantin Noica, Ed. Ştiinţifică şi Enciclopedică, Bucureşti, 1989.

${ }^{2}$ Spunem o parte din aceste obiceiuri pentru că adunarea tuturor acestor credințe, dincolo că ni se pare imposibil de realizat dată fiind dinamica acestora, presupune un volum uriaş de informaţii, pe de o parte, iar pe de altă parte, presupune și maturitate în domeniul etnografiei şi folclorului. Totodată, a le trata pe toate dar în mod expeditiv, considerăm că nu face un serviciu, ci, din contră, ar lăsa multe lacune.

${ }_{3}^{3}$ Istoricul american Paul MacKendrick avea să pornească în activitatea de cercetare de la premisa certă că “ pietrele dacilor au început să grăiască”. Un singur lucru i se cere istoricului: dacă se apucă să scrie, este dator să se închine doar adevărului. Pe scurt, o singură regulă, un singur îndreptar să-l îndrume: "să privească nu spre cititorii din vremea lui, ci spre oamenii care îi vor citi scrierile în viitor". Paul MACKENDRICK, Pietrele dacilor vorbesc, trad. Horia Florian Popescu, Ed. Ştiinţifică şi Enciclopedică, Bucureşti, 1978, p. 7.

${ }^{4}$ Lucian Blaga menţionează că elemente precum dor, jale, urât, sunt intraductibile în altă limbă. Poporul ipostaziază dorul; Lucian BLAGA, Trilogia culturii. Spaţiul mioritic, vol II, Ed. Humanitas, București, 1994, pp. 160-161.
} 
ceas de Taină sau de Sărbătoare. De asemenea, putem concluziona asemenea lui Thomas Mann care, elogiind Viața, spunea că boala şi Moartea (apropierea Morţii) sunt „marii educatori”, însemnate călăuze preţioase către ceea ce este omenesc, dar și de sublinierea lui Schopenhauer, unde spunea că dacă n-ar fi existat moartea pe Pământ, cu greu s-ar concepe și existența filosofiei.

Epifenomenul VIAȚĂ - MOARTE. Literatura de specialitate este relativ bogată în ceea ce privește fenomenologia Morții, înmormântarea, credințele și ritualurile specifice, iar etapa de documentare îmi dă posibilitatea de a reda, în cele ce urmează, o listă de autori români și străini, pe care îi vom putea regăsi, alături de alte surse primare, directe și indirecte și la Bibliografia finală:

P.S. †Calinic Botoşăneanul, Tanatologia si proiecţiile sale filozofico-teologice, teză de doctorat, Ed. Cantes, Iaşi,1998; Pr. Constantin Galeriu, Jertfă şi răscumpărare, Ed. Harisma, Bucureşti, 1991; Cardinal Joseph Ratzinger, La mort et l'au-delà, Éd. Fayard, Paris, 1994; Irina Petraş, Ştiinţa morţii, Ed. Dacia, ClujNapoca, 1995; Arnold van Gennep, Riturile de trecere, trad. Lucia Berdan, Ed. Polirom, Iaşi, 1998; Ludmila Romanciuc-Dutcovschi, Folclor din Moldova, Ed. Arc, Chișinău, 2012; Mozes Gaster, Studii de folclor comparat, Ed. Saeculum I.O., București, 2003; Jean-Claude Larchet, Sfârșit creștinesc vieții noastre, fără durere, neînfruntat, în pace..., trad. Marinela Bojin, Ed. Basilica, București, 2012; Luiza Maria Dumitru, Sacrul monstruos. (Mitologie, mitistorie, folclor românesc), Ed. Paideia, București, 2007; Pr. Emanuel Valică, Tanatologia creștină între istorie, ritualul înmormântării, simbolism și actualitate. Abordare liturgico-pastorală, Ed. Christiana, București, 2013; Pr. Ilie Macar, Sfârșitul omului și al lumii între adevăr și utopie. Eshatologie și erezie, Ed. Doxologia, Iași, 2014; Pr. Filoteu Faros, Moartea și doliul. O teologie a nădejdii, trad. Pr. Victor Manolache, Ed. Sophia, București, 2012; Ioan Viorel Boldureanu, Cultură tradițională orală. Teme, concepte, categorii, Ed. Marineasa, Timișoara, 2006; Nicolae Panea, Gramatica funerarului, Ed. Scrisul românesc, Craiova, 2003; Jean-Miguel Garringues, $A$ l'heure de notre mort. Accueillir la vie éternelle, Collection Vie spirituelle, Éditions de l'Emmanuel, Paris, 2000 ; Emmanuel Levinas, Moartea şi timpul, trad. Adrian Mănuţiu, Ed. Apostrof, Cluj-Napoca, 1996 ; Seraphim Rose, Sufletul după moarte. Experienţele post-mortem contemporane, în lumina învățăturii ortodoxe cu privire la viaţa de apoi, trad. Constantin Jinga, Ed. Anastasia, Bucureşti, 2002 ; Valeriu Sârbu, Credințe și practici funerare, religioase și magice in lumea geto-dacilor, Ed. Porto-Franco, Galați, 1993; Delia Suiogan, Simbolica ritualurilor de trecere, Ed. Paideia, București, 2006; Romulus Vulcănescu, Mitologie română, Ed. Academiei, București, 1985; Simeon Florea Marian, Înmormântarea la români. Studiu etnografic, Ed. Grai și Suflet, București, 1995; Philippe Ariés, Omul în faţa morţii, trad. şi note Andrei Niculescu, Ed. Meridiane, Bucureşti, 1996; Arhim. Vasilios Baicoianis, Sufletul după moarte, trad. Pr. Victor Manolache, Ed.Tabor, București, 2013; Ion Biberi, Viaţa şi moartea în evoluţia universului, Ed. Enciclopedică Română, București, 1971; Mircea Eliade, Arta de a muri, Ediţie îngrijită, selecţie de texte şi note de Magda Ursache şi Petru Ursache, Ed. Moldova, Iaşi, 1993 ; Jean Zigler, Les Vivants et la mort. Essai de Sociologie, Éditions du Seuil, Paris, 1975 etc.

Moartea poate fi definită ca epifenomen, ${ }^{1}$ dar şi ca eveniment, dacă o introducem într-o formulare a mass-mediei contemporane, care constituie adevărate ,treceri obligate, garantate ale existenței ritului, părți componente ale construcției sociale și istorice ale evenimentului" ${ }^{2}$ funerar. Omul modern şi cu mult mai mult creştinul, trebuie să o trateze mai puţin ,tehnologic" şi mai mult în sens personal, ca pe o experienţă de Viață. Asta pentru că Moartea este un fapt de Viață, unul personal care ne privește pe fiecare în parte. Trecerea de la statuarea noţiunii de „Moarte” la experierea realitătii ei este, probabil, printre lucrurile cel mai greu de împlinit în Viața de pe Pământ, pentru că cel mai adesea noi vorbim despre Moarte la modul anonim şi abstract, ca despre un obiect sau o problemă oarecare, banală prin frecvența ei.

Paradoxurile istoriei nu surprind în totalitate dihotomia Viață - Moarte, de aceea reamintim că tot civilizația elenă ne mai surprinde cu un aspect legat de percepția echilibrului dintre ele deoarece în Antichitate grecii ,au avut un ochi și pentru seriozitatea și tragismul Vieții”. ${ }^{3}$ Unii dintre istoricii Morţii, antropologi şi tanatologi consideră că în ultimele decenii se afirmă o adevărată „redescoperire a Morţii””. De pildă, Edgar Morin considera că una dintre primele descoperiri ale lui homo sapiens a fost aceea a Morţii şi că odată cu înmormântarea se naşte cultura - prin întrebările legate de Moarte, prin felul în care în jurul acestor reflecţii se constituie primele credinţe religioase şi expresiile lor culturale, prin spaţiul

\footnotetext{
${ }^{1}$ Epifenomen - neologism de origine franceză, (épiphénomène), care se definește semiotic drept un fenomen secundar care însoțește un fenomen esențial (Viața), fără să-1 influențeze. Desigur, mulți ar spune că Viața ia sfârșit prin Moarte, dar Mântuitorul, Apostolii, Sf. Părinți, corifeii gândirii filosofice precum și datele științei (până la punctul de unde îi încep limitele) califică Moartea ca prag, trecere spre adevărata Viață.

2 Pascal LARDELLIER, Teoria legăturii ritualice: antropologie și comunicare, trad. Valentina Pricopie, Ed. Tritonic, București, 2003, p. 136.

${ }^{3}$ Diac. Prof. Dr. Nicolae BALCA, Istoria filosofiei antice, EIBMBOR, București, 1982, p. 136.
} 
în care se fac înhumările ca loc social.1 În actualitate, aceasta ar fi un efect al „mişcării tanatologice” care face parte dintr-un fenomen social mai vast, mişcare care se justifică printr-o critică (de anvergură) a postmodernităţii. Din punct de vedere epistemic, știința despre Moarte, sau Tanatologia ${ }^{2}$ are rădăcini nebănuite în cultura și civilizația umană, iar într-o formulă ancestrală o regăsim în practicile funerare egiptene.

Conceptual, știința și termenul de Tanatologie sunt atestate chiar înainte de sfârşitul secolului al XVIII-lea. Prin 1795, Salomon Anschel, ilustru medic din Göttingen, vorbeşte despre Tanatologie întro lucrare care a avut oarecare răsunet în epocă: „Thanatologia sive mortis naturam, causas, genera ac species et diagnosis disquisitions”. Interesul asupra acestei cărți vine nu doar din faptul că furnizează etiologia maladiilor letale şi semiologia Morţii. Autorul ei ne face părtaşi la cercetările sale pe animale moarte şi la tentativa de criogenizare a creierului - ceea ce reprezintă o anticipare cu adevărat uluitoare a cercetărilor moderne.

O abordare strict conceptuală arată că Moartea, încă din imemorialele timpuri ale credinţelor primitive, nu însemna o încetare a Vieţii, ci doar trecerea într-o stare diferită. ${ }^{3}$ Acelaşi aspect îl reflectă şi mitologia antică a numeroase popoare, care avea să-şi pună din plin amprenta şi pe cugetarea filosofică a primelor veacuri ale civilizaţiei. Tocmai din acest motiv, concepţiile antropologice începând de la Pitagora şi Socrate (şi continuând în epoca modernă până la Henry Bergson, Karl Jaspers şi Martin Heidegger) vor defini „Moartea” drept o umbră care însoțeşte întreaga existenţă umană. ${ }^{4}$ La rândul ei, viziunea creștină asupra Morţii rezolvă foarte multe dintre angoasele omului. ${ }^{5}$ Moartea unui tânăr sau a unei persoane mature scandalizează mereu. Ce să mai spunem de războaie, de calamităti sau de ucideri în masă? Ştiinţa şi medicina modernă îşi revendică rădăcinile poziţionate în cadrul cultural al umanismului dar depinde însă, din perspectiva cărei formule epistemice o va face: din perspectiva cunoaşterii ştiinţifice sau din perspectiva cunoaşterii prin credinţă. ${ }^{6}$

Din punct de vedere epistemic, istoricii și filosofii religilor - prin care cei mai de seamă reprezentați ai renumitei Religionsgeschichtliche Schule (Klaus Kesler, Wilhelm Brandt, Richard Reitzenstein, Wilhelm Anz, Hans Jonas, Wilhelm Bousset) - au încercat să abordeze problematica deosebit de complexă a sacrului, a Vieții și a Morții abordându-le în chip diferit. Amintesc aici și pe cei care, din perspectiva hermeneutică (ex. : M. Eliade) și-au propus abordarea sacrului din perspectiva unei morfologii și a unei tipologii a hierofaniilor, pentru a evidenția mai ales dorinţa omului religios de a trăi ,într-o lume sanctificată, adică într-un spaţiu sacru”, , fie o perspectivă sociologică (Émile Durkheim, Roger Caillois ${ }^{9}$ ) pornind de la societatea primitivă ca loc de naștere a sacrului, a riturilor și ritualurilor ${ }^{10}$, implicit a religiei, în fine cea fenomenologică (Rudolf Otto, Nathan Söderblom, Gerardus van der Leeuw) - atunci când se încerca analiza fenomenului religios în context existențial.

Un răspuns coerent și argumentat epistemic, capabil să ne ofere o perspectivă asupra moștenirii tradițiilor de înmormântare, mai ales în simbolistica dar și în poetica epodelor muzicale specifice unor anumitor etape ritualice, îl putem formula din analiza religiei geto-dacilor, pornind de la modul cum concepeau şi trăiau ei credinţa în nemurire. Aproape pretutindeni unde amintesc despre geto-daci, scriitorii antici nu uită să adauge calificativul de nemuritori. ${ }^{11}$ Desigur, ideea de nemurire caracterizează, cu diferenţele şi nuanţele de rigoare, toate popoarele lumii, dintotdeauna şi de pretutindeni, dar la getodaci ea devine principiul ordonator al Vieţii. Potrivit documentelor antice, vitejia soldaţilor geto-daci se

\footnotetext{
${ }^{1}$ Edgar MORIN, L'homme et la mort, Seuil, Paris, 1970, pp. 55-62, apud Mihaela GRANCEA, Sensul morții. Cercetări tanatice clasice, analize despre o nouă ars moriendi, în rev. Transilvania, nr. 7/2009, p. 33.

2 Definiţia științifică a Tanatologiei este următoarea: Disciplină medico-legală care se ocupă cu studiul Morţii şi a fenomenelor şi proceselor care au loc în corpul uman după moarte.

${ }^{3}$ Alfred BERTHOLET, Dicţionarul religiilor, trad. Gabriel Decuble, Ed. Universităţii „Al.I. Cuza” Iaşi, 1995, p. 290.

${ }^{4}$ Octavian CHEŢAN şi Radu SOMMER (coord.), Dicţionar de filosofie, Ed. Politică, Bucureşti, 1978, p. 465.

${ }^{5}$ Dacă martirul se defineşte în raport cu moartea, iar ascetul o consideră drept un punct de referinţă, şi, în acelaşi timp, calea spre Împărăţia Cerurilor, călugărul face din Moarte un exerciţiu spiritual pentru fiecare zi. Pentru martir, Moartea nu poate fi decât bună, însă pentru călugăr ea nu este nici bună nici rea în sine. Ca şi pentru omul simplu, cel ce „suferă” Moartea îi conferă o valoare anume. Cf. Cristian BĂDILIȚĂ, Călugărul şi moartea, Ed. Polirom, Iaşi, 1998, p. 38.

${ }^{6}$ Thierry MAGNIN, Intre ştiinţă şi religie, trad. Simona Modreanu, Ed. Junimea, Iaşi, 2007, p. 18.

7 Școala de Istorie a Religiilor, înființată în secolul al XIX-lea (1886) de către Albert Eichhorn, William Wrede, Hermann Gunkel, Alfred Ralhfs, Johannes Weiß la Universitatea din Göttingen, care-şi formulează propria direcție de cercetare.

${ }^{8}$ Mircea ELIADE, Sacrul și profanul, trad. Brândușa Prelipceanu, Ed. Humanitas, București, 1995, p. 18.

${ }^{9}$ A se vedea Roger CAILLOIS, Omul și sacrul, trad. Dan Petrescu, Ed. Nemira, București, 2006.

${ }^{10}$ Émile DURKHEIM, Forme elementare ale vieții religioase, trad. Magda Jeanrenaud și Silviu Lupescu, Ed. Polirom, Iași, 1995 , p. 45.

${ }^{11}$ HERODOT, Istorii, (IV,94 - IV,96), apud Silviu SANIE, Din istoria culturii şi religiei geto-dacice, ed. a II-a, Ed. Universităţii „Al. I. Cuza”, Iaşi, 1999, pp. 252-253.
} 
baza tocmai pe credinţa lor în nemurire. Astfel, Împăratul Iulian Apostatul (361-363) pune în gura Împăratului Traian (98 -117) următoarele cuvinte referitoare la nemurirea geților şi vitejia lor: „Am nimicit neamul geţilor, care au fost mai războinici decât oricare oameni ce au trăit cândva - şi aceasta nu numai datorită tăriei trupului lor, dar şi pentru că îi convinsese să fie astfel slăvitul Zalmoxis. Crezând că nu mor, dar că îşi schimbă doar locuinţele, ei sunt mai porniţi pe lupte decât ar fi înclinaţi să întreprindă o călătorie." ${ }^{\prime 1}$ Nemurirea dacică, ca şi cea germanică sau scitică era una celestă, fapt care generează o întrebare firească: sub ce formă și în ce condiții parcurgea sufletul imensele distanţe până la locul de destinaţie? Sufletul pleca într-o lume mai bună, de aceea Moartea geto-dacului era însoţită de ritualuri şi de o filosofie aparte cu privire la Viaţă şi Moarte. Se spune că era incinerat fiindcă aşa sufletul său - Pasărea Sufletului - călătorea mai uşor către divinităţile aflate în văzduh. Răspunsul categoric poate fi descoperit în incinta sacră de la Sarmisegetusa Regia şi la Fețele Albe, pe care sunt redate în relief 7 orbite planetare şi Pasărea Sufletului. Dimensiunile acestor piese, singurele sculpturi din artă dacică, sunt de $21 \mathrm{~cm}$. înălţime, 25 lungime şi $20 \mathrm{~cm}$ lăţime. Pasărea Sufletului sculptată pe cele două fețe teşite ale semicalotei este foarte stilizată. Este uşor de recunoscut gâtul păsării împreună cu vârfurile aripilor ridicate spre cer.

Tributar lui Herodot, Pomponius Mela spunea despre traci că atitudinea lor se datoreşte credinţelor lor deosebite; unii cred că sufletele celor care mor se vor întoarce pe pământ, iar alţii socotesc că, deşi nu se vor întoarce, ele nu se sting, ci merg în locuri mai fericite; alţii cred că sufletele mor negreşit, însă că e mai bine aşa decât să trăiască. ${ }^{2}$ Istoricul Silviu Sanie ţine să precizeze că, în cazul concepţiei ultime, că sufletele totuşi mor, nu este vorba decât de un fel de platonism popular, respectiv un pesimism popular de extracție existențialistă, o Mioriță avant la lettre.

Balada a fost culeasă pentru prima oară de Alecu Russo şi publicată de Vasile Alecsandri, dar intervenţia poetului este minimă şi numai exterioară, esenţa viziunii mioritice aparține exclusiv folclorului. La fel și ciobanul care folosește aceeași alegorie a Morții și a Nunții cosmice, binecunoscută în istoria literaturii universale și în fenomenologia religiilor. El moare simbolic pentru a se uni cu divinitatea adorată, zeitatea feminină din ceruri sau care, în alte variante, apare pe munte împodobită cu simboluri solare și lunare. Este vorba de o hierogamie (să ne reamintim Luceafărul eminescian), adică bineștiuta Nuntă a sufletului omului cu o Divinitate cerească. ${ }^{3}$ Aceasta pentru că omul a vrut încă din cele mai vechi timpuri să-şi transpună imaginea în coordonate cosmice. În literatura folclorică, această tendinţă a fost materializată prin mai multe motive şi mituri. Printre ele se întâlnește cel al proiectării în eternitate prin eros şi prin thanatos. Simbolismul Nunţii cosmice este admirabil descris în balada populară a Mioriţei printr-un mixaj de mituri şi simboluri arhetipale. Concluzia lui Eliade e că „balada Mioriţa este ea însăşi rezultatul unui proces creator... care, la o anumită epocă, a efectuat transmutaţia unui comportament ritual primar într-o capodoperă poetică, încărcată de semnificaţii noi şi purtătoarea unui mesaj mai bogat şi mai „elevat.”4 „Mioriţa” mai este considerată cântecul bătrânesc al poporului român şi are o funcţie estetică analoagă cu cea a epopeilor antice. Este de asemenea un simbol al existenţei pastorale al poporului român ce exprima viziunea franciscan-panteistică a morţii la individul român după cum afirmă şi George Călinescu. Aceste interacţiuni nu trebuie să se desfăşoare la întâmplare ci sunt reglementate şi direcţionate în interesul societăţii, astfel încât aceasta să nu sufere lezări. ${ }^{5}$ La fel, se manifestă continuităţi, de această dată în planul literar, a ideii de sacrificiu, al uciderii cu valenţe ritualice. O percepție asemănătoare a avut și Lucian Blaga când ne vorbea despre categoriile abisale ale cunoașterii, ele având rolul de mediator între Adevăr și proiecția acestuia în conștiință, deoarece, prin intermediul acestora se anclanșează censura transcendentă care îngrădește aprehensibilitatea umanului, limitat astfel la o percepție indirectă, sublimată simbolic, metaforic.

Ca popor, încă mai avem o protoistorie vie şi încă creatoare în folclor ${ }^{6}$, iar această creaţie populară, dacă s-ar aduna la un loc, s-ar constata că mitologia şi epopeea neamului sunt unite într-o originală viziune cosmică. ${ }^{7}$ Complexitatea materiei cercetate, ,o complexitate care implică moduri foarte diferite de receptare şi cunoaştere", implică un grad de obiectivitate şi o gradare firească a hiperbolei frazeologice. Aceasta și pentru „faptul că studiile folclorice, de la cele mai naive până la cele mai riguros ştiinţifice, se deosebesc foarte mult între ele ca metodologie, orientare generală sau

\footnotetext{
${ }^{1}$ Nicolae ACHIMESCU, Istoria şi filosofia religiei la popoarele antice, Ed. Tehnopress, Iaşi, 2000, pp. 228-229.

${ }^{2}$ Pomponius MELA, Descrierea Pământului, (II,2,18), apud Silviu SANIE, Din istoria culturii şi religiei geto-dacice, p. 259.

${ }^{3}$ Cf. Victor RAVINI, Miorița. Izvorul nemuririi, Ed. ALCOR IMPEX, București, 2016, pp.122-134.

${ }^{4}$ Mircea ELIADE, De la Zalmoxis la Genghis-Han Studii comparative despre religiile şi folclorul Daciei şi Europei Orientale, trad. Maria Ivănescu şi Cezar Ivănescu, Ed. Humanitas, Bucureşti, 1995, p. 233.

${ }^{5}$ Arnold van GENNEP, Riturile de trecere, trad. Lucia Berdan şi Nora Vasilescu, Ed. Polirom, Iaşi, 1998, p. 16.

${ }^{6}$ Stelian BABOI, Spiritualitatea morală a poporului român, Ed. Edict, Iaşi, 2002, p. 144.

${ }^{7}$ Cf. Ibidem, p. 150.
} 
delimitare a obiectului. “1 Folclorul, în contextul culturii populare româneşti este o carte deschisă spre un orizont spiritual, adresându-se, ,în totalitatea ei sau prin anumite capitole de interes particular, tuturor specialiştilor în probleme de etnografie şi folclor sau celor care doresc să se iniţieze în aceste domenii, indiferent de preocupările lor curente." ${ }^{3}$

Concluzii. Meditaţia asupra timpului, asupra Vieții și a Morții este regăsită la toate nivelurile existențiale, pentru că de ea depinde abordarea sensurilor religiosului în general. Ne străduim să studiem faptele istoriei religioase ca atare, adică în planul lor specific de manifestare, de aceea totul se manifestă în concretul istoric, şi totul ne apare condiţionat de o istorie a omenirii care in nuce conține fragmente ale istoriei sacre în timp ce, paradoxal, se regăsește ea însăși cuprinsă în aceasta. O serie întreagă de credințe, obiceiuri şi practici religioase ale strămoşilor noştri s-au sedimentat, ca după o furtună a istoriei, în folclorul românesc. Peste aceste credinţe s-a aşternut, ca o velinţă sfântă, Creştinismul care, blând şi îngăduitor, după porunca Mântuitorului, le-a tolerat caracterul arhaic (păgân sună prea peiorativ) şi, sensibil, le-a creştinat şi le-a valorificat simbolistica metafizică, pentru că folclorul nu este decât metafizica dacilor zamolxieni sublimată în epode, tradiții, cutme și acte ritualice.

Concepţiile românilor despre Moarte nu sunt unitare, dar se unesc în sistemul de credinţe şi obiceiuri ce-i însoţesc pe cei ce au gustat Moartea, pentru că de fapt, au pregustat din izvoarele istoriei și folclorului geto-dac. Această permanentă întoarcere la origini l-a făcut pe țăranul român să regăsească și să transmită esenţa sacră a lucrurilor, dar nu sacrul Bisericii, ci un tip aparte, care-i permite omului să se apropie de absolut. Tradițiile de înmormântare aduc la aceeași masă pe Hristos și pe Zamolxes, cu sau fără voia Sfintei Biserici. În istoria culturii românești, folclorul a fost identificat ca un fenomen autonom, componentă a culturii universale. El nu este un dat exclusiv al culturii noastre, nu aparţine numai culturii europene, este un fenomen care ţine de universalitate. Folclorul este cartea de vizită a poporului român, cântul nostru popular, atât de dulce, atât de cald, asemuit cu ciripitul ciocârliei, regăsit în doină, dar și-n bocetul funebru, are amprenta identității noastre ca neam.

\section{BIBLIOGRAFIE}

1. Achimescu, N., Istoria și filosofia religiilor la poparele antice, 2000, Ed. Tehnopress, Iași, p.228-229;

2. Baboi, S., Spiritualitatea morală a poporului român, 2002, Ed. Edict, Iași, p.144;

3. Balca, N., Istoria filosofiei antice, 1982, Ed. Eibmbor, București, p.136;

4. Bădeliță, C., Călugărul și moartea, 1998, Ed. Polirom, Iași, p.38

5. Bertholet, A., Dicționarul religiilor, trad. Decuble, G., 1995, Ed. Universității Al.I.Cuza, Iași, p.290;

6. Blaga, L., Trilogia culturii. Spațiul mioritic, vol. II, 1994, Ed. Humanitas, București, p. 160-161;

7. Chețan, O., Sommer, R., Dicționar de filosofie, 1978, Ed. Politehnică, București, p.465;

8. Durkheim, E., Forme elementare ale vieții religioase, trad. Jeanrenaud, M, Lupescu, S., 1995, Ed. Polirom, Iași, p.18;

9. Eliade, M., Sacrul și profanul, trad. Prelipceanu, B., 1995, Ed. Humanitas, București, p.18;

10. Herodot, Istorii (IV,94-IV,96) apud. Sanie, S., 1999, Ed. Universității Al.I.Cuza, Iași, p.252-253;

11. Lardellier, P., Teoria legăturii ritualice: antropologie și comunicare, trad. Pricopie, V., 2003, Ed. Titonic, București, p.136;

12. Magmin, T., Între știință și religie, trad. Modreanu, S., 2007, Ed. Junimea, Iași, p.18;

13. Mela, P., Descrierea pământului $(I I, 2,18)$ apud. Sanie, S., p.259;

14. Morin, E., L'homme et la mort, 1970, Seuil, Paris, p.55-62;

15. Platon, Theaitetos (152a), trad. Noica, C., 1989, Ed. Științifică și enciclopedică, București;

16. Ravini, V., Miorița. Izvorul nemuririi, 2016, Ed. Alcor Impex, București, p. 122-134;

17. Rudăndoiu, P., Folclorul literar în contextual culturii populare românești, 2001, Ed. Grai și suflet, București, p. 19.

\footnotetext{
${ }^{1}$ Pavel RUXĂNDOIU, Folclorul literar în contextul culturii populare româneşti, Colecţia „Cuminţenia Pământului“, Ed. Grai şi suflet - Cultura Naţională, Bucureşti, 2001, p. 19.

${ }^{2}$ Ibidem, p. 6.
} 